\title{
The effect of octylated diphenylamine and Irganox 1520 antioxidants on the stability of polybutadiene rubber
}

\author{
Alireza Fazlali $^{1}$ (i) $\cdot$ Vahab Ghaleh Khondabi $^{1} \cdot$ Mohammad Javad Sharifi ${ }^{2} \cdot$ Mohammad Amir Nikoohemmat $^{1}$
}

Received: 14 June 2018 / Accepted: 16 January 2019 / Published online: 13 February 2019

(c) The Author(s) 2019

\begin{abstract}
One of the serious problems in polybutadiene rubber (PBR) production units is the color change in products, which is due to aging and the inability of antioxidants to protect the product, especially at high temperatures. In this study, the effects of amine-type antioxidant [octylated diphenylamine (OD)] and non-amine-type antioxidant (Irganox 1520) on the color yellowness, gel content and thermal stability of PBR, at concentrations of 500, 1000, 1500, 2500 and $4000 \mathrm{ppm}$, at temperature of $110{ }^{\circ} \mathrm{C}$, and different aging times $(1-10 \mathrm{~h})$ were investigated. The results showed that the polymer with $\operatorname{Irganox} 1520$ antioxidant has a higher thermal stability, less gel formation and lower color than polymer containing OD antioxidant; therefore, the Irganox 1520 antioxidant was more suitable.
\end{abstract}

Keywords Antioxidant · Color yellowness · Gel content · Irganox · Octylated diphenylamine · Polybutadiene rubber · Stability

\section{Introduction}

Nowadays, polybutadiene products are used in the manufacture of various catalysts. One of the catalytic systems used is cobalt acetate, which uses antioxidant for the stability of the polymer [1]. The stabilizers of polymers should effectively protect polymers from various, mostly radical-degrading, processes, be compatible with the polymer, and persist in the polymer [2-5]. Antioxidants in the polymerization reactions are compounds that are used to inhibit the reaction between polymers and free air oxygen. The oxidation process can be carried out at all stages of the existence of a polymer from the moment of manufacture up to the time of consumption and cause unwanted changes in the chemical, mechanical and electrical properties of the polymer [6-8]. If, for any reason, the antioxidant is not injected into the polymer, the product is dark brown after a short time and its physical and mechanical properties are practically altered. The reason for this is the destruction of the polymer by oxidation and the

Alireza Fazlali

a-fazlali@araku.ac.ir

1 Department of Chemical Engineering, Faculty of Engineering, Arak University, Arāk, Iran

2 Department of Chemical Engineering, Faculty of Engineering, Tehran University, Tehran, Iran change of nature $[9,10]$. Even a simple monophosphate antioxidant such as butylated hydroxytoluene (BHT) may also reduce the antioxidant activity and create a quinone system, which can act as a color agent in the polymer [11-13].

Octylated diphenylamine $(\mathrm{C} 28 \mathrm{H} 43 \mathrm{~N})$ is a medium activity, amine-type antioxidant for general-purpose elastomer use. It is antioxidant for natural rubber (NR), styrene-butadiene rubber (SBR), nitrile-butadiene rubber (NBR) and chloroprene rubber (CR). It has good protective character to heat, oxygen, flexing and crazing, and is efficient to rubber whether used together with carbon black [14]. It has obvious thermal brittleness resistance in CR, and can increase its protective character to ozone aging. It is also used as antioxidant and corrosion inhibitor in saline and synthetic lubricants, and as a general-purpose for non-blooming anti degrading in both black and non-black stocks, and in latex applications [9].

Irganox 1520 (C25H44OS2) is a multifunctional phenolic antioxidant for organic substrates such as elastomers, plastics, adhesives, sealants, oils and lubricants. It effectively protects the substrate against thermo-oxidation during processing and long-term heat aging. It is non-staining, non-discoloring, low in volatility, and stable to light and heat. Irganox 1520 is an effective stabilizer in a wide range of solution polymerized, emulsion polymerized and thermoplastic elastomers including butadiene rubber (BR), 
styrene-butadiene rubber (SBR), nitrile-butadiene rubber (NBR), isoprene rubber (IR), styrene-butadiene-styrene (SBS) and styrene-isoprene-styrene (SIS), as well as natural rubber $[14,15]$. It can be used with other additives such as secondary antioxidants, benzofuranone, light stabilizers and other functional stabilizers, the recommended dosage level of which is $0.05-0.3 \%[16,17]$.

In this work, considering that the technical knowledge of the use of antioxidants was related to the past two decades, attempts have been made to find antioxidants more favorable than the antioxidants used in the technologies available in the polybutadiene production industry.

\section{Materials and methods}

\section{Preparation of the samples}

Polybutadiene (Shazand Petrochemical Company, Iran) and toluene (99/8\%, Sigma-Aldrich) as solvents, Irganox 1520 as a phenolic antioxidant (99\%, Basel, Switzerland) and an octylated diphenylamine as an amine antioxidant (98\%, Richem, Shanghai china) were used as main materials. First, $20 \mathrm{~g}$ of polybutadiene was dissolved in $300 \mathrm{~cm}^{3}$ of toluene and the appropriate amount of antioxidant was added to it, and then in the nitrogen gas atmosphere, the sample of the toluene solvent was dried. After drying, the sample was placed in an oven at $110^{\circ} \mathrm{C}$ for aging times of $2,4,6,8$, and $10 \mathrm{~h}$. The aging method was carried out in a manner similar to that described in ASTM D1693, ASTM D573 tests for plastic materials.

\section{Analytical methods}

Measurement of solution color was performed with a UV Spectrophotometer (DR 4000) at a wavelength of $600 \mathrm{~nm}$, based on ASTM D1209-00 [18]. For estimation of gel content, some of the samples were made in the form of narrow strings $(W)$ and dissolved in toluene, then filtered it through the sieve with $50-\mu \mathrm{m}$ mesh $\left(W_{1}\right)$, and weighed again after washing, filtering and drying $\left(W_{2}\right)$. Gel content was calculated as a percentage by weight [19]:

Gel content $(\%)=\frac{W_{2}-W_{1}}{W} \times 100$.

Differential scanning calorimetry thermal analysis is a method in which material changes at different temperatures are investigated over time. Differential scanning calorimetry was performed with a DSC (METTLER-TC11) at $30-300{ }^{\circ} \mathrm{C}\left(10{ }^{\circ} \mathrm{C} / \mathrm{min}\right)$ and atmospheric pressure [20].

\section{Results and discussion}

\section{Effect of antioxidants on color yellowness}

Figure 1 shows the effect of antioxidant on the color of the solution of polybutadiene at different concentrations at $110^{\circ} \mathrm{C}$. By increasing the aging time from 1 to $5 \mathrm{~h}$ at a specific concentration of both antioxidant types, the amount of coloration in the polymer matrix containing Irganox 1520 and OD increases from 6 to 11 and from 7 to 13, respectively, which in fact indicates the negative effect of time on the antioxidant activity. However as shown in Fig. 1a-d, increasing concentration from 500 to $2500 \mathrm{ppm}$ at a given time does not have a significant effect on the color index and sometimes reduces it. By comparing the figures, it can be said that at all times and concentrations, the color index in Irganox 1520 was always lower than OD, which indicates its advantage.

One of the main factors in the creation of color in the composition of polybutadiene is the destruction of the antioxidant and the conversion into the quinone system due to the presence of these products resulting from the destruction of antioxidants, and because of the absorption of light in the visible region, it creates color in the polymer matrix. Figure 2 shows the mechanism for the formation of a quinone system in the OD antioxidant [21]. As shown in Fig. 2, conjugate bonds in the OD structure formed by the resonance with the aromatic system reduce the energy level of molecular orbitals $(\pi)$ and antibonding molecular orbital $\left(\pi^{*}\right)$ and transfer the maximum absorption to longer wavelengths; eventually, they absorb into the visible region, and hence produce color in the PBR product.

The Irganox 1520 antioxidant due to the existence of the functional phenolic group in its chemical structure (Fig. 3) [22] can acts as a first-type antioxidant, and on the other hand, because of the functional sulfide group, it also acts as a secondary type of antioxidant. The presence of the functional group in the ortho and para positions, relative to the formation of a quinone system, shows more resistance, which is one of the important factors of color formation.

\section{Effect of antioxidants on gel content}

Figure 4 shows the effect of antioxidant on the gel content of polybutadiene solution in different concentrations at $110^{\circ} \mathrm{C}$. By increasing the aging time from 2 to $10 \mathrm{~h}$ at a specific concentration of both antioxidants, the gel content of polymer with Irganox 1520 and OD increases from 0.5 to $2.5 \%$ and from 0.5 to $4 \%$, respectively, which in fact indicates the negative effect of time on the antioxidant activity. However Fig. 4a-d show that increasing concentration from 500 to $2500 \mathrm{ppm}$ at a given time does not have a significant effect 

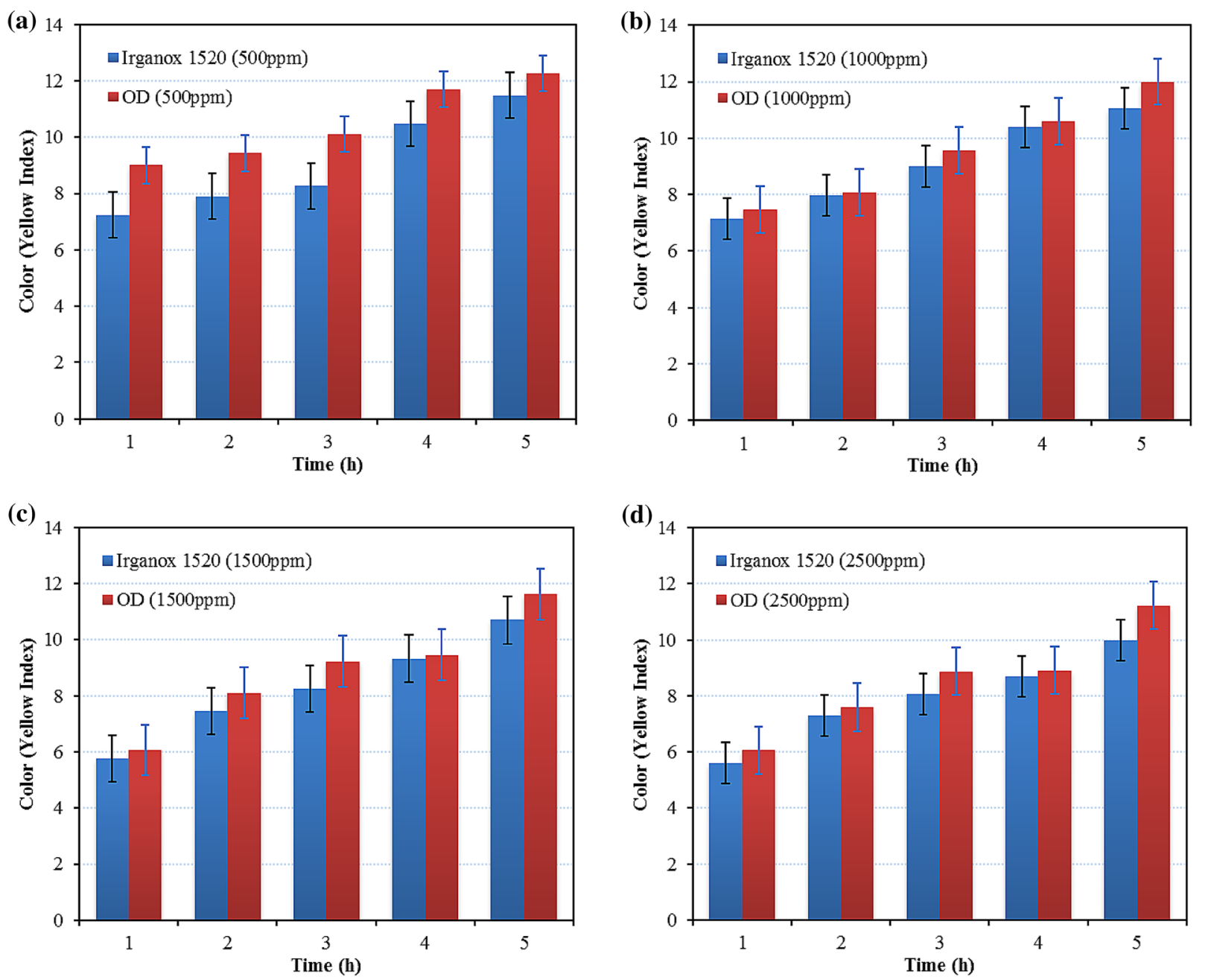

Fig. 1 Effect of IRGANOX 1520 and OD on PBR color at $110^{\circ} \mathrm{C}$ and concentration of a $500 \mathrm{ppm}, \mathbf{b} 1000 \mathrm{ppm}, \mathbf{c} 1500 \mathrm{ppm}$ and d $2500 \mathrm{ppm}$

on the gel content and sometimes reduces it. By comparing the figures and considering that the mechanism of destruction in polybutadiene is the type of cross-link formation, the Irganox 1520 antioxidant creates less gel in the polymer system and has a better performance than OD antioxidant.

\section{Thermal analysis: differential scanning calorimetry}

Figures 5 and 6 show DSC thermograms for both antioxidants at a temperature range of $30-300{ }^{\circ} \mathrm{C}$ with a temperature rise rate of $10{ }^{\circ} \mathrm{C} / \mathrm{min}$. It is clear by refering to the therogram of DSC test, the resulting thermogram appears as a positive peak, that whatever the grater destruction in the polybutadiene chain, the higher number of cross-link, and its exothermic enthalpy peak increases. As previously stated, the type of destruction mechanism in polybutadiene is based on the formation of cross-link between polymeric chains, and as the process of destruction goes up, crosslink increases and more energy is released into the system; however, if the antioxidant has less enthalpy, the more effective it will be.

Figure 7 shows the relationship between the enthalpy, and the antioxidant type and its concentration. As shown in this figure, with increasing concentration of each antioxidant from 500 to 4000 ppm, enthalpy destruction decreases from 213.5 to $120.4 \mathrm{~J} / \mathrm{g}$ and from 247.6 to $122 \mathrm{~J} / \mathrm{g}$ for Irganox and OD, respectively, but in identical concentrations, the enthalpy of the Irganox 1520 is less than the OD, which indicates that Irganox 1520 antioxidant system protects the polymer against thermal degradation better than OD antioxidant. It can also be said that, due to the non-amine-type antioxidant, Irganox 1520, having hydroxyl and thioether electron donors, relative to the OD, in which nitrogen acts as an electron donor, therefore it has a more stable radical and a better performance, and the results show this very well. 
Fig. 2 Mechanism of OD inhibitory effect in the polymer system

Fig. 3 Mechanism of IRGANOX 1520 inhibitory effect in the polymer system
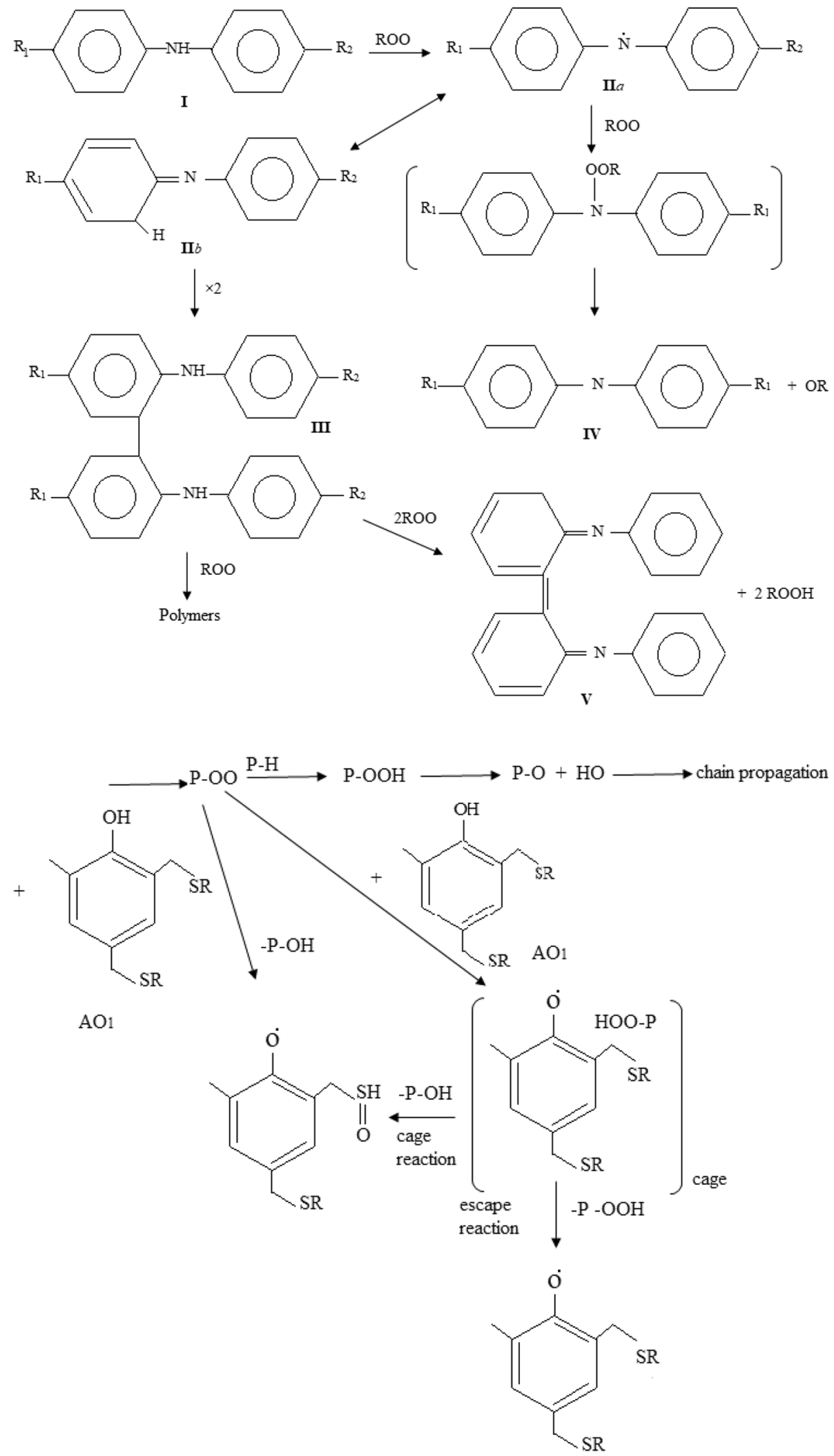
(a)

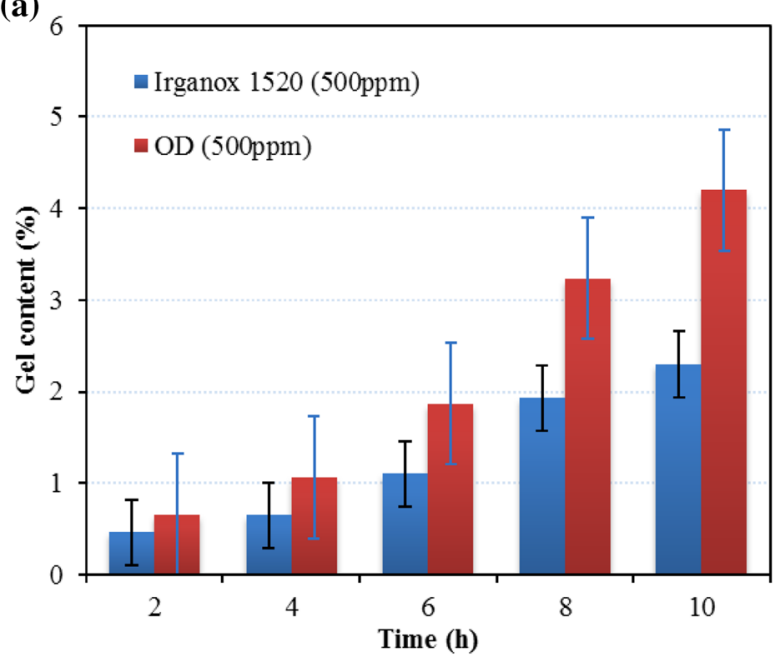

(c)

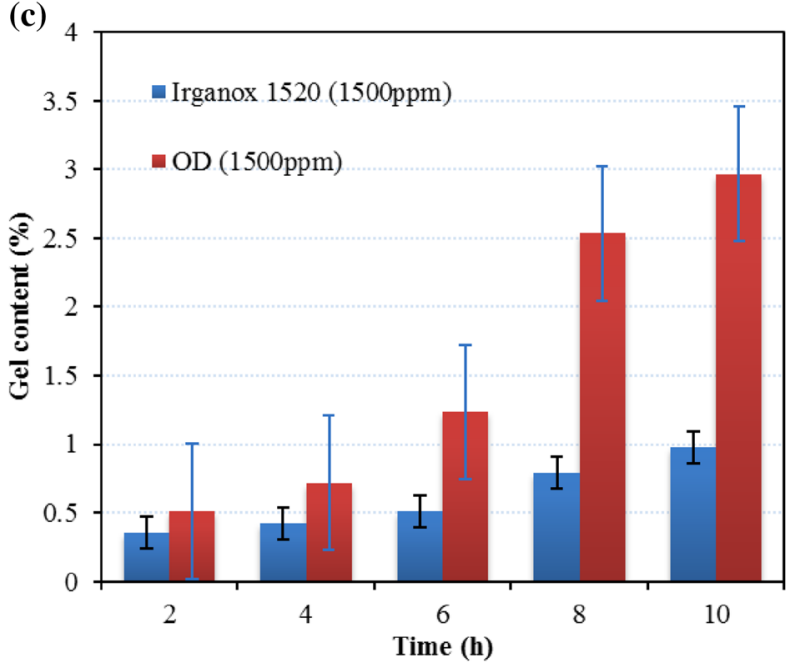

(b)

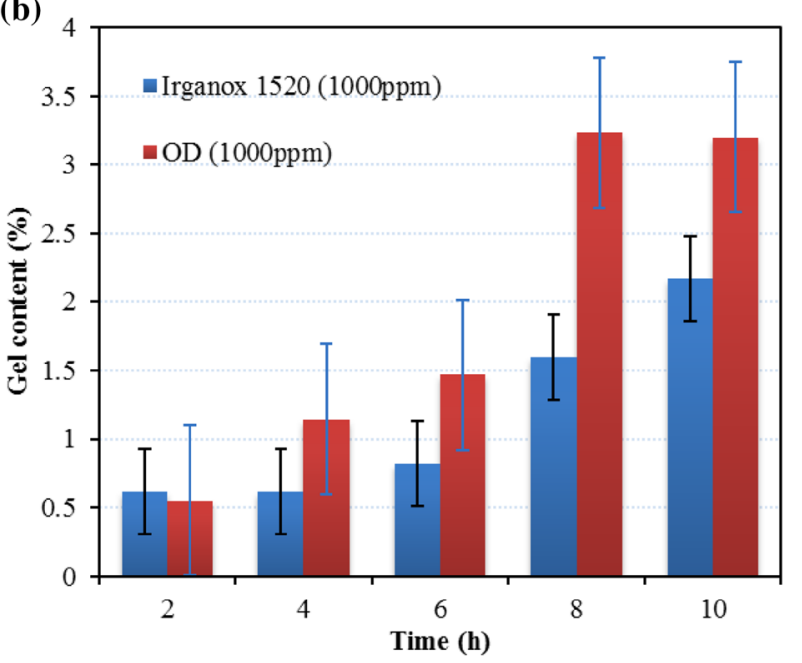

(d)

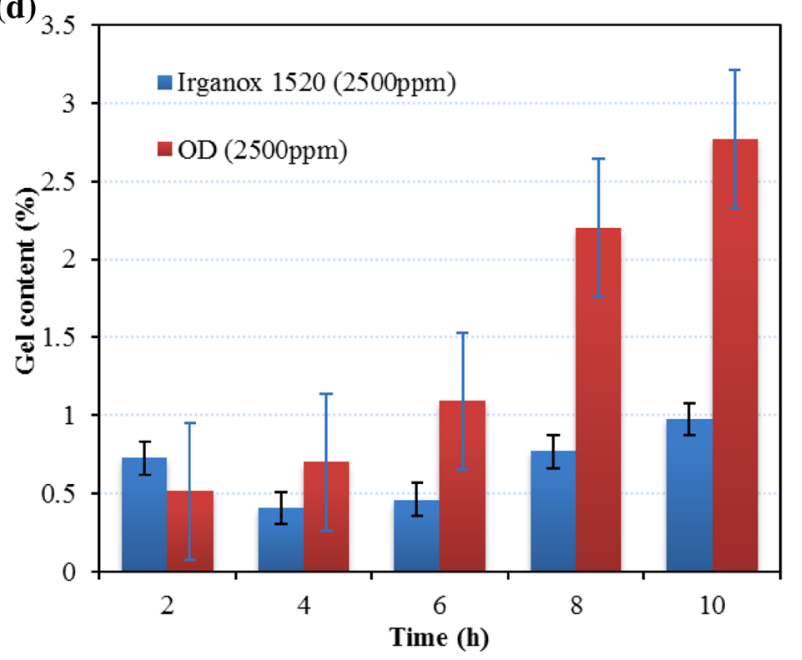

Fig. 4 Effect of IRGANOX 1520 and OD on PBR gel content at $110{ }^{\circ} \mathrm{C}$ and concentration of a 500 ppm, b 1000 ppm, c 1500 ppm and d $2500 \mathrm{ppm}$

\section{Conclusions}

In this investigation, the performance of amine-type (OD) and non-amine-type (Irganox 1520) antioxidants in improving the stability of Polybutadiene was studied. Experiments were carried out at $110^{\circ} \mathrm{C}$, atmospheric pressure, aging time of $1-10 \mathrm{~h}$, and $500-4000 \mathrm{ppm}$ of antioxidant concentrations. The result of experiments demonstrated the superiority of Irganox 1520 relative to OD antioxidant.

By increasing the time at a specific concentration of both antioxidant types, the amount of coloration in the polymer matrix is increased, but by increasing the concentration of both antioxidants at a given time, the amount of color decreases. It can be said that at different times and concentrations, the color produced by the Irganox 1520 antioxidant is less than $\mathrm{OD}$, which indicates better performance.

By increasing the time at a specific concentration of both antioxidants, the gel content increases in the polymer, while by increasing the concentration of both antioxidants at a given time, the amount of gel decreases. At all times and concentrations, the gel content in Irganox 1520 was always lower than OD, which indicates its advantage.

By increasing the concentration of both antioxidants, enthalpy destruction decreases, but in identical 
Fig. 5 DSC thermogram of PBR containing 500 ppm OD

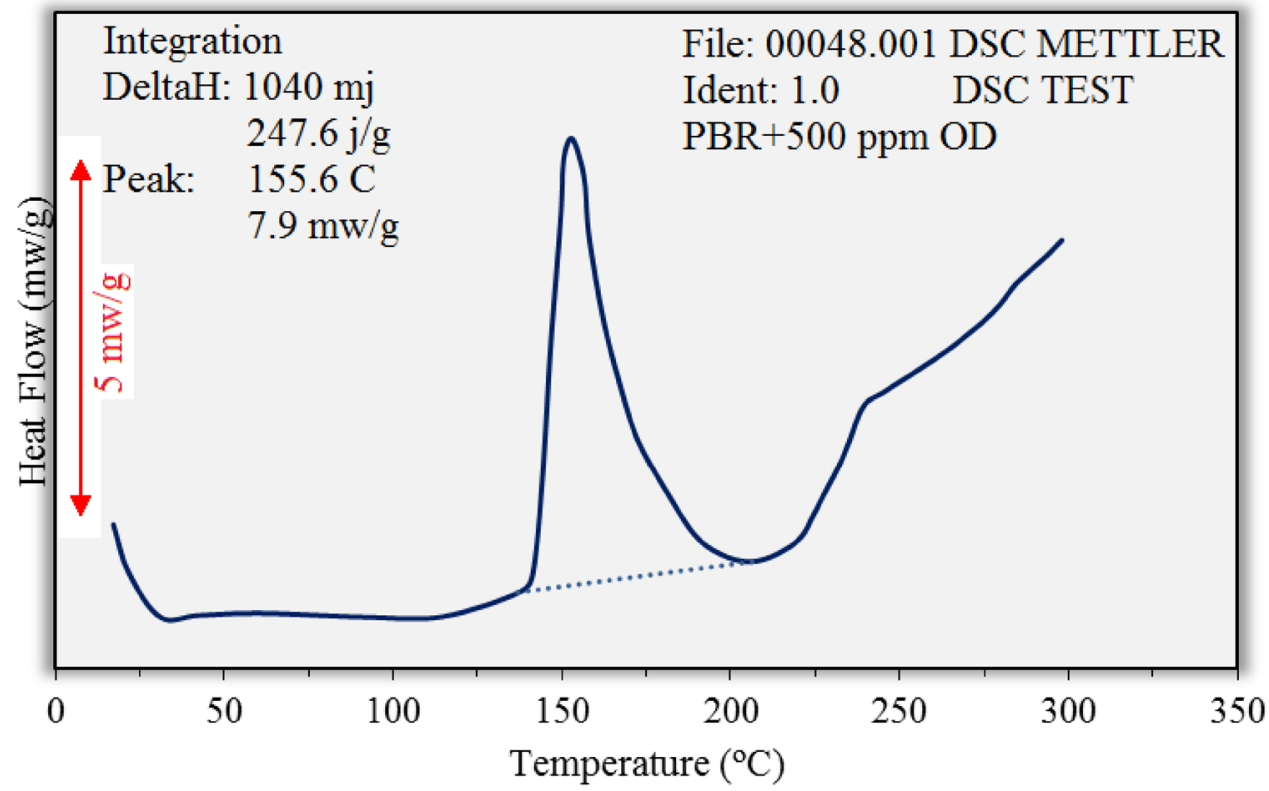

Fig. 6 DSC thermogram of PBR containing $4000 \mathrm{ppm}$ Irganox 1520

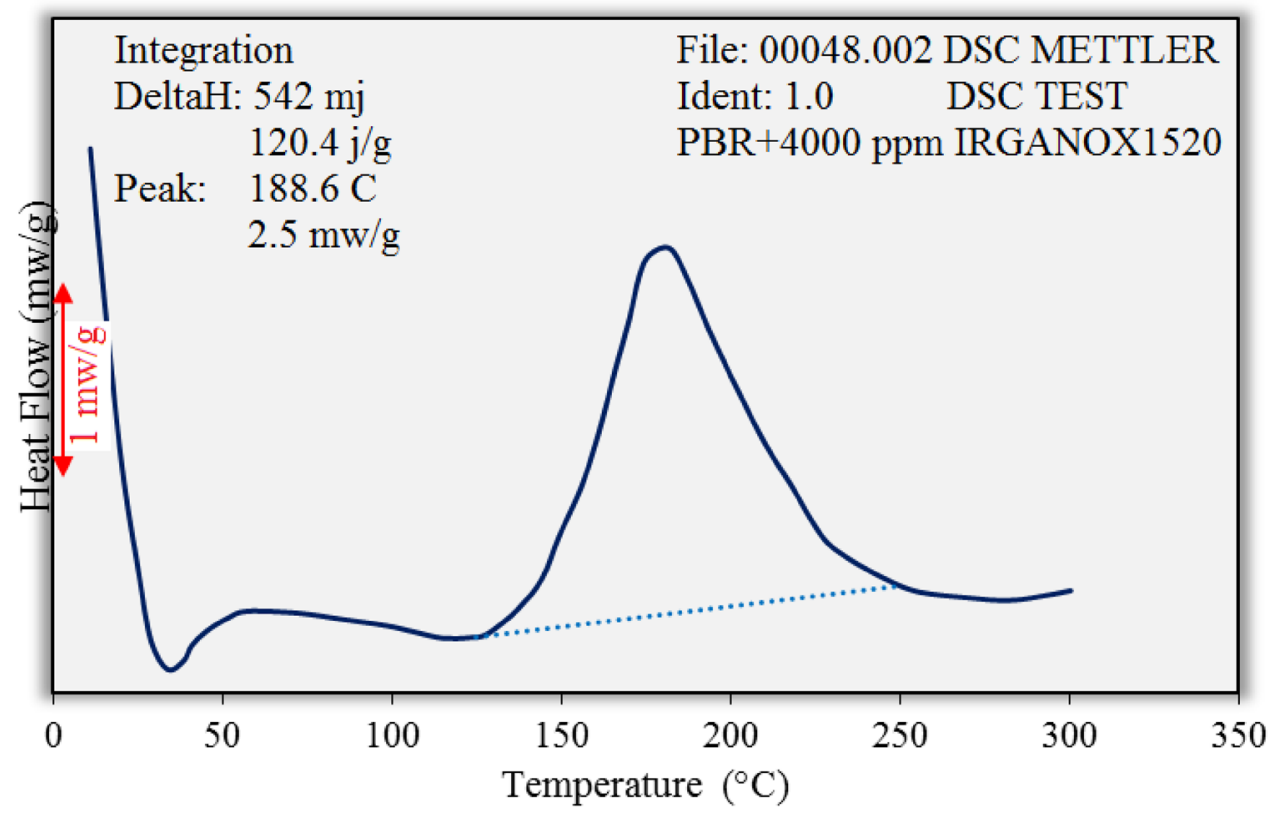

concentrations, the enthalpy of the Irganox 1520 is less than the OD, which indicates its better performance.

According to the experiments, the Irganox 1520 consumption range is $1500-2500 \mathrm{ppm}$. Using more amounts does not significantly affect the stability of the product and only increases the antioxidant use and, as a result, increases the cost. 


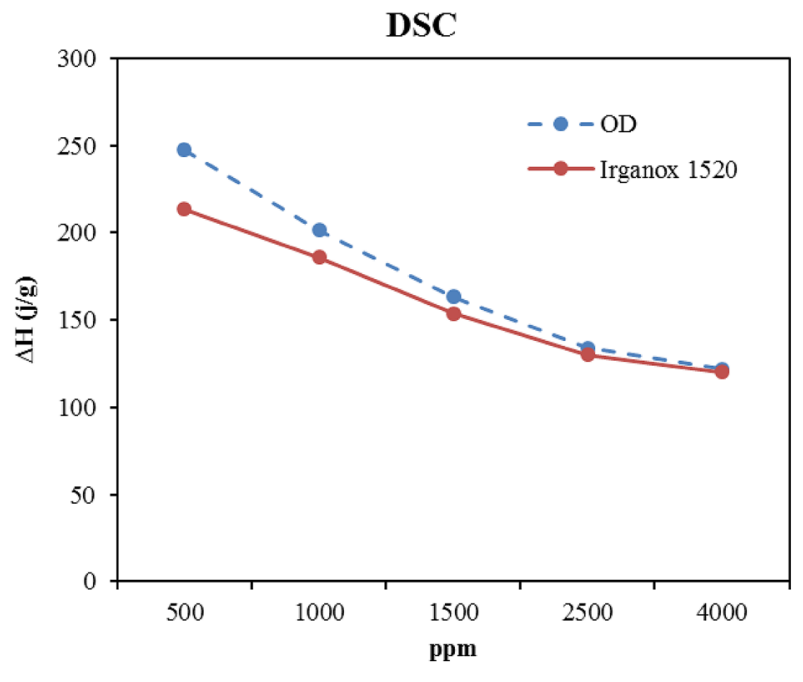

Fig. 7 The enthalpy of two antioxidant systems: Irganox 1520 and OD

Open Access This article is distributed under the terms of the Creative Commons Attribution 4.0 International License (http://creativeco mmons.org/licenses/by/4.0/), which permits unrestricted use, distribution, and reproduction in any medium, provided you give appropriate credit to the original author(s) and the source, provide a link to the Creative Commons license, and indicate if changes were made.

\section{References}

1. Sulekha PB, Joseph R, Manjooran KB (2004) New oligomerbound antioxidants in natural rubber/polybutadiene rubber and natural rubber/styrene-butadiene rubber blends. J Appl Polym Sci 93:437-443. https://doi.org/10.1002/app.20427

2. Brandt HD, Nentwig W, Rooney N, LaFlair RT, Wolf UU, Duffy J, Puskas JE, Kaszas G, Drewitt M, Stephan G (2011) Rubber, 5. Solution rubbers. Ullmann's encyclopedia of industrial chemistry. Wiley. https://doi.org/10.1002/14356007.o23_o02

3. Maiti M, Jasra R (2011) High-cis polybutadiene rubber in benign solvents and process for preparation thereof. Patent US20120296055 A1

4. Singh A, Modi S, Subrahmanyam N, Munshi P, Upadhyay VK, Jasra RV, Maiti M (2010) Retarding effect of aromatic solvents on cobalt(II)-based catalyst system during synthesis of high $\mathrm{cis}$ 1,4-polybutadiene. Ind Eng Chem Res 49:9648-9654. https://doi. org/10.1021/ie101324d

5. Srivastava VK, Maiti M, Basak GC, Jasra RV (2014) Role of catalysis in sustainable production of synthetic elastomers. J Chem Sci 126:415-427. https://doi.org/10.1007/s12039-014-0580-5

6. Das PK, DesLauriers PJ, Fahey DR, Wood FK, Cornforth FJ (1995) Photostabilization of poly ( $p$-phenylene sulfide). Polym Degrad Stab 48:1-10. https://doi.org/10.1016/01413910(95)00032-H

7. Saunier J, Mazel V, Aymes-Chodur C, Yagoubi N (2012) Blooming of Irganox $3114^{\circledR}$ antioxidant onto a medical grade elastomer. Impact of the recrystallization conditions on the antioxidant polymorphism, on the film wettability and on the antioxidant leachability. Int J Pharm 437:89-99. https://doi.org/10.1016/j.ijpha rm.2012.07.060
8. Mark HF (2004) Encyclopedia of polymer science and technology: acoustic properties to cyclopentadiene and dicyclopentadiene, vol 5. Wiley, pp 163-168. https://doi.org/10.1002/0471440264

9. Malik J, Krohnke C (2006) Polymer stabilization: present status and possible future trends. C R Chim 9:1330-1337. https://doi. org/10.1016/j.crci.2006.02.009

10. Subudhi AW, Jacobs KA, Hagobian TA, Fattor JA, Fulco CS, Muza SR, Rock PB, Hoffman AR, Cymerman A, Friedlander AL (2004) Antioxidant supplementation does not attenuate oxidative stress at high altitude. Aviat Space Environ Med 75:881-888

11. Lairez D, Adam M, Emery JR, Durand D (1992) Rheological behavior of an epoxy/amine system near the gel point. Macromolecules 25:286-289. https://doi.org/10.1021/ma00027a046

12. Moudgalya KM, Jaguste S (2001) A class of discontinuous dynamical systems II. An industrial slurry high density polyethylene reactor. Chem Eng Sci 56:3611-3621. https://doi.org/10.1016/ S0009-2509(01)00044-6

13. Muller R, Gerard E, Dugand P, Rempp P, Gnanou Y (1991) Rheological characterization of the gel point: a new interpretation. Macromolecules 24:1321-1326. https://doi.org/10.1021/ma000 $06 \mathrm{a} 017$

14. Gruver JT, Rollmann KW (1964) Antioxidant properties of carbon black in unsaturated elastomers. Studies with cis-polybutadiene. J Appl Polym Sci 8:1169-1183. https://doi.org/10.1002/ app.1964.070080311

15. Fu Y, Yang C, Lvov YM, Zhang L, Wang W (2017) Antioxidant sustained release from carbon nanotubes for preparation of highly aging resistant rubber. Chem Eng J 328:536-545. https:// doi.org/10.1016/j.cej.2017.06.142

16. Podesva J, Kovarova J (2003) Synthesis and performance of phenolic polybutadiene-bound stabilizers. J Appl Polym Sci 87:885889. https://doi.org/10.1002/app.11342

17. Podesva J, Kovarova J, Hrdlickova M, Netopilik M (2009) Stabilization of polyurethanes based on liquid OH-telechelic polybutadienes: comparison of commercial and polymer-bound antioxidants. Polym Degrad Stab 94:647-650. https://doi.org/10.1016/j. polymdegradstab.2009.01.003

18. ASTM D1209-05 (2011) Standard test method for color of clear liquids (platinum-cobalt scale). ASTM International, West Conshohocken. http://www.astm.org. https://doi.org/10.1520/D1209 $-05 R 11$

19. ASTM D2765-16 (2016) Standard test methods for determination of gel content and swell ratio of cross linked ethylene plastics. ASTM International, West Conshohocken. http://www.astm.org. https://doi.org/10.1520/D2765-16

20. ISO 11357-3 (2011) Plastics-differential scanning calorimetry (DSC)-part 3: determination of temperature and enthalpy of melting and crystallization. International Organization for Standardization. http://www.iso.org

21. Cibulkova Z, Simona P, Lehocky P, Balko J (2005) Antioxidant activity of $p$-phenylenediamines studied by DSC. Polym Degrad Stab 87:479-486. https://doi.org/10.1016/j.polymdegradstab .2004.10.004

22. Meier H, Dubs P, Kunzi H, Martin R, Knobloch G, Bertterman H, Thuet B, Borer A, Kolczak U, Rist G (1995) Some aspects of a new class of sulfur containing phenolic antioxidants. Polym Degrad Stab 49:1-9. https://doi.org/10.1016/0141-3910(95)00058 $-\mathrm{T}$

Publisher's Note Springer Nature remains neutral with regard to jurisdictional claims in published maps and institutional affiliations. 